\title{
INFLUÊNCIA DA TEMPERATURA NO CRESCIMENTO DA MICROALGA Spirulina sp. LEB 18
}

\author{
M. M. FONTOURA ${ }^{1}$, A. L. CORRÊA ${ }^{1}$, M. C. VEIGA $^{1}$ e L. O. SANTOS $^{1}$ \\ ${ }^{1}$ Universidade Federal do Rio Grande, Escola de Química e Alimentos \\ E-mail para contato: santoslucielen@gmail.com
}

\begin{abstract}
RESUMO - Microalgas são consideradas um dos mais eficientes sistemas biológicos de transformação de energia solar em compostos orgânicos, pois quando cultivadas em condições adequadas certas espécies podem duplicar sua biomassa diariamente. A cianobactéria Spirulina possui em sua composição nutricional aminoácidos essenciais, vitaminas, pigmentos, ácidos graxos poliinsaturados e sais minerais, bem como elevado teor proteico, por isso a adição da biomassa desta cianobactéria em alimentos torna-se interessante. Diferentes temperaturas durante o cultivo microalgal vêm sendo estudadas com o objetivo de aumentar o crescimento microalgal e a eficiência de seu cultivo. Neste estudo foi utilizada a microalga Spirulina sp. LEB 18, mantida em meio Zarrouk e cultivada em fotobiorreatores tubulares de $2 \mathrm{~L}$, com volume útil de $1,8 \mathrm{~L}$ durante $16 \mathrm{~d}$. Foram testadas temperaturas de 30 e $35{ }^{\circ} \mathrm{C}$. Foram feitas análises para determinação da concentração celular e $\mathrm{pH}$. A concentração de biomassa máxima $\left(\mathrm{X}_{\text {máx }}\right)$ foi $1,02 \pm 0,04 \mathrm{~g} \mathrm{~L}^{-1}$ utilizando a temperatura de $30^{\circ} \mathrm{C}$ e $1,01 \pm 0,02 \mathrm{~g} \mathrm{~L}^{-1} \mathrm{a}$ $35^{\circ} \mathrm{C}$. O pH dos cultivos ficou na faixa de 9,6 a 10,23.
\end{abstract}

\section{INTRODUÇÃO}

Microalgas são micro-organismos fotossintetizantes com requerimento nutricional relativamente simples. A biomassa microalgal e os biocompostos obtidos a partir dela destinam-se a diversas aplicações, como suplemento alimentar para humanos, ração animal, produção de biocombustíveis, tratamento de águas residuais e biocorantes (BERTOLDI et al., 2008). A cianobactéria Spirulina é reconhecida como GRAS (Generally Recognized as Safe) pelo FDA (Food and Drug Administration) o que permite sua utilização em formulações alimentares. A utilização da biomassa de Spirulina em alimentos torna-se interessante em comparação com a produção convencional de proteínas, pois esta microalga necessita de água, luz, dióxido de carbono e nutrientes inorgânicos para se desenvolver (CHRONAKIS; MADSEN, 2011).

Fatores como temperatura, iluminação, $\mathrm{pH}$ e disponibilidade de nutrientes no meio durante cultivo microalgal, podem influenciar no crescimento e na composição da biomassa de microalgas. Neste contexto, alguns parâmetros nos cultivos vêm sendo modificados com o objetivo de estimular o crescimento e induzir a produção de biomoléculas de interesse. Dentre estes parâmetros destaca o uso de diferentes temperaturas no meio de cultivo (COLLA et al., 2007). 
Para que os componentes do meio de cultura sejam devidamente absorvidos, deve-se controlar o pH, o qual é influenciado pelas proporções entre formas de carbono dissolvidas na água de cultivo. $\mathrm{O}$ consumo do $\mathrm{CO}_{2}$ afeta diretamente o crescimento das microalgas e como consequência, modifica o $\mathrm{pH}$ do sistema (LOURENÇO, 2006). Com isso o objetivo do trabalho foi avaliar a influência de diferentes temperaturas $\left(30\right.$ e $\left.35^{\circ} \mathrm{C}\right)$ no crescimento da microalga Spirulina sp. LEB 18.

\section{MATERIAIS E MÉTODOS}

\subsection{Micro-organismos e condições de cultivo}

Neste estudo foi utilizada a cianobactéria Spirulina sp. LEB 18 isolada da Lagoa Mangueira localizada no município de Santa Vitória do Palmar - RS (MORAIS et al., 2008). $\mathrm{O}$ inóculo foi mantido em frasco erlenmeyer de $2 \mathrm{~L}$, com volume útil de $1,8 \mathrm{~L}$, a $30{ }^{\circ} \mathrm{C}$ e utilizando meio de cultivo Zarrouk (ZARROUK, 1966), sob iluminância de $60 \mu \mathrm{mol} \mathrm{m}^{-2} \mathrm{~s}^{-1} \mathrm{e}$ fotoperíodo $12 \mathrm{~h}$ claro/escuro.

Os cultivos foram realizados durante 16 dias em fotobiorreatores tubulares verticais de $2 \mathrm{~L}$ e volume útil de $1,8 \mathrm{~L}$, com iluminância de $30 \mu \mathrm{mol} \mathrm{m} \mathrm{m}^{-2} \mathrm{~s}^{-1}$ e fotoperíodo $12 \mathrm{~h}$ claro/escuro. Os ensaios foram mantidos em estufas termostatizadas, onde foram testadas as temperaturas de 30 e $35^{\circ} \mathrm{C}$. Para a aeração dos cultivos foi utilizada a vazão de $0,3 \mathrm{vvm}$ (volume de ar volume de meio ${ }^{-1} \min ^{-1}$ ) e a concentração celular inicial foi $0,2 \mathrm{~g} \mathrm{~L}^{-1}$.

A evaporação da água durante o cultivo foi controlada por meio da manutenção do volume das culturas com reposição diária de água destilada estéril. Os cultivos foram realizados em triplicata. Diariamente foi retirada amostra de $5 \mathrm{~mL}$ de cada fotobiorreator para avaliação da concentração celular e pH.

\subsection{Determinações analíticas}

A concentração de biomassa foi determinada mediante leitura da densidade ótica dos cultivos em espectrofotômetro, com comprimento de onda de $670 \mathrm{~nm}$ (MORAIS et al., 2008), utilizando curva padrão que relaciona a densidade ótica e a massa seca de biomassa.

$\mathrm{O} \mathrm{pH}$ dos cultivos foi avaliado por meio da leitura direta em pHmetro digital.

\subsection{Avaliação dos parâmetros de crescimento}

Os parâmetros determinados nos cultivos foram: a produtividade máxima $\left(\mathrm{P}_{\text {máx }}\right)$ (Equação 1), velocidade específica máxima de crescimento ( $\left.\mu_{\text {máx }}\right)$ (Equação 2$)$, concentração de biomassa máxima $\left(\mathrm{X}_{\text {máx }}\right)$ e tempo de geração $\left(\mathrm{t}_{\mathrm{g}}\right)$ (Equação 3$)$.

$$
P_{m a x}=\frac{\left(X-X_{0}\right)}{\left(t-t_{0}\right)}
$$




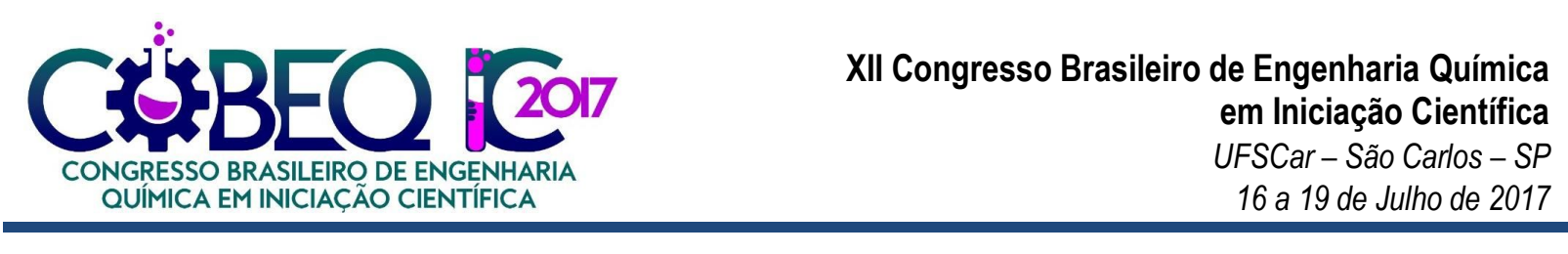

$H_{\text {max }}=\frac{1}{x} \cdot \frac{d x}{d t}$

$t_{g}=\frac{h_{(2)}}{\mu_{\text {max }}}$

\subsection{Avaliação dos parâmetros de crescimento}

As respostas obtidas nos ensaios foram avaliadas por análise de variância (ANOVA) e por teste de Tukey para comparação entre médias, com nível de significância de $95 \%$ de confiança.

\section{RESULTADOS E DISCUSSÃO}

A Figura 1 apresenta a concentração de biomassa de Spirulina sp. LEB 18 ao longo do tempo de cultivo. Ao analisar esta Figura foi possível observar que houve crescimento celular desde o início do cultivo. A maior concentração de biomassa foi encontrada no $16^{\circ} \mathrm{d}$ nas duas temperaturas testadas.

Figura 1. Concentração de biomassa de Spirulina sp. LEB $18 \mathrm{em}$ temperatura de $30^{\circ} \mathrm{C}$ (o) e $35^{\circ} \mathrm{C}(\mathrm{x})$.

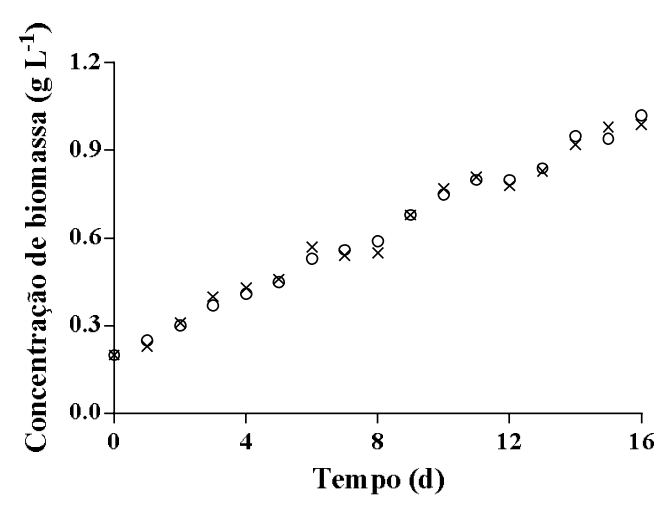

Conforme pode ser observado na Tabela 1, não houve diferença significativa no crescimento da microalga, portanto é possível cultivar a cianobactéria Spirulina sp. LEB 18 utilizando ambas as temperaturas para a produção de biomassa. Segundo Vonshak (1997), a temperatura ótima para o crescimento desta cianobactéria encontra-se entre $30^{\circ} \mathrm{C}$ e $35^{\circ} \mathrm{C}$.

Apesar da concentração não diferir significativamente, a composição da biomassa pode ser diferente. Ao utilizar a temperatura de $35^{\circ} \mathrm{C}$, Colla et al. (2007) reportaram aumento na concentração de proteína da biomassa de Spirulina (74\%), em comparação com a temperatura de $30{ }^{\circ} \mathrm{C}(62 \%)$. 
Tabela 1. Concentração de biomassa máxima $\left(\mathrm{X}_{\text {máx }}\right)$, produtividade máxima $\left(\mathrm{P}_{\text {máx }}\right)$, velocidade específica máxima de crescimento $\left(\mu_{\text {máx }}\right)$ e tempo de geração $\left(t_{\mathrm{g}}\right)$ obtidos nos cultivos de Spirulina sp. LEB 18 utilizando 30 e $35^{\circ} \mathrm{C}$.

\begin{tabular}{|l|c|c|}
\hline & $30^{\circ} \mathrm{C}$ & $35^{\circ} \mathrm{C}$ \\
\hline $\mathrm{X}_{\text {máx }}\left(\mathrm{g} \mathrm{L}^{-1}\right)$ & $1,02 \pm 0,04^{\mathrm{a}}$ & $1,01 \pm 0,02^{\mathrm{a}}$ \\
\hline $\mathrm{P}_{\text {máx }}\left(\mathrm{g} \mathrm{L}^{-1} \mathrm{~d}^{-1}\right)$ & $0,05 \pm 0,0^{\mathrm{a}}$ & $0,05 \pm 0,00^{\mathrm{a}}$ \\
\hline$\mu_{\text {máx }}\left(\mathrm{d}^{-1}\right)$ & $0,18 \pm 0,03^{\mathrm{a}}$ & $0,19 \pm 0,02^{\mathrm{a}}$ \\
\hline $\mathrm{t}_{\mathrm{g}}(\mathrm{d})$ & $4,01 \pm 0,74^{\mathrm{a}}$ & $3,62 \pm 0,32^{\mathrm{a}}$ \\
\hline
\end{tabular}

Letras minúsculas iguais representam que não há diferença significativa entre colunas a $95 \%$ de confiança $(\mathrm{p}<0,05)$

Em estudo anterior, Karam e Soccol (2007) estudaram o efeito de diferentes temperaturas $\left(20^{\circ} \mathrm{C}, 25^{\circ} \mathrm{C}, 30^{\circ} \mathrm{C}\right.$ e $\left.35^{\circ} \mathrm{C}\right)$ para o cultivo de Spirulina platensis, porém as maiores concentrações de biomassa foram encontradas nas temperaturas de $30^{\circ} \mathrm{C}\left(1,17 \mathrm{~g} \mathrm{~L}^{-1}\right)$ e $35^{\circ} \mathrm{C}\left(0,93 \mathrm{~g} \mathrm{~L}^{-1}\right)$. A partir destes resultados, optou-se por avaliar as temperaturas de $30^{\circ} \mathrm{C} \mathrm{e}$ $35^{\circ} \mathrm{C}$ no presente estudo.

A Figura 2 apresenta o $\mathrm{pH}$ dos cultivos de Spirulina sp. LEB 18 ao longo do tempo de cultivo. Percebe-se que a faixa de $\mathrm{pH}$ variou de 9,61 a 10,23 em ambos cultivos. $\mathrm{O} \mathrm{pH}$ do cultivo deve ser mantido alcalino, pois esta microalga cresce de forma natural em ambientes com elevada salinidade e alcalinidade (VONSHAK, 1997). Segundo Costa et al. (2002), o cultivo de Spirulina deve ser realizado em pH entre 8,3 e 11,0, pois nesta faixa a cianobactéria possui maior taxa fotossintética.

Figura 2. Faixa de pH dos cultivos de Spirulina sp. LEB 18 em temperatura de $30^{\circ} \mathrm{C}$ (o) e 35 ${ }^{\circ} \mathrm{C}(\square)$.

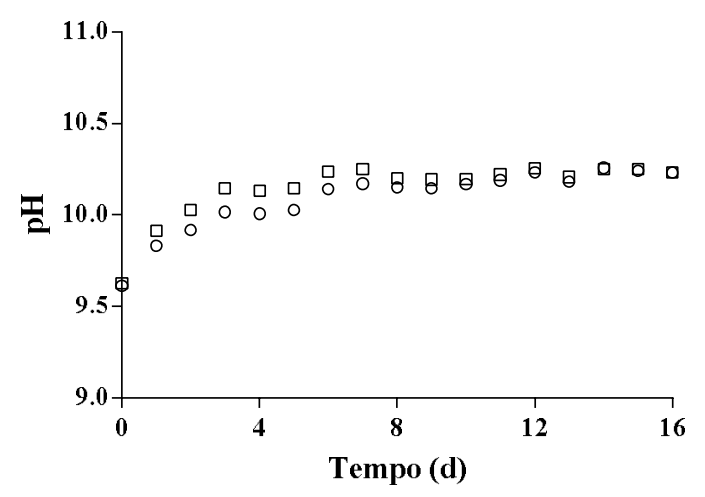

\section{CONCLUSÃO}

A utilização de diferentes temperaturas $\left(30\right.$ e $\left.35^{\circ} \mathrm{C}\right)$ não influenciou no crescimento da microalga Spirulina sp. LEB 18 durante 16 d de cultivo, porém será realizada a 
caracterização da biomassa afim de verificar se ocorreram modificações na composição em função da temperatura.

\section{REFERÊNCIAS}

BERTOLDI, F.; SANT'ANNA, E.; OLIVEIRA, J. Revisão: Biotecnologia de Microalgas. $B$. Ceppa, v. 26, n. 1, p. 9-20, 2008.

CHRONAKIS, I. S.; MADSEN, M. Algal proteins. In: PHILLIPS, G. O.; WILLIAMS, P. A. Handbook of Food Protein. [S.I.] Woodhead Publishing Series in Food Sciences, Technology and Nutrition, p. 353-394, 2011.

COLLA, L. M.; REINEHR, C. O.; REICHERT, C.; COSTA, J. A. V. Production of biomass and nutraceutical compounds by Spirulina platensis under different temperature and nitrogen regimes. Bioresource Technology, v. 98, n. 7, p. 1489-1493, 2007.

COSTA, J. A. V.; COLLA, L. M.; DUARTE FILHO, P.; KABKE, K.; WEBER, A. Modeling of Spirulina platensis growth in fresh water using response surface methodology. World Journal Microbiology and Biotechnology, v. 18, p. 603-607, 2002.

KARAM, L. M.; SOCCOL, C. R. Efeito da temperatura e pH no cultivo de Spirulina major. Arq. Ciênc. Vet. Zool., v. 10, n. 1, p. 5-7, 2007.

LOURENÇO, S. O. Cultivo de Microalgas Marinhas: Princípios e Aplicações. São Carlos: RiMa, 2006.

VONSHAK, A. Spirulina platensis (Arthrospira): physiology, cell-biology and biotechnology. London: Taylor \& Francis, 1997.

ZARROUK, C., 1966. Contribution à l'étude d'une cyanophycée. Influence de divers facteurs physiques et chimiques sur la croissance et la photosynthèse de Spirulina maxima. Ph.D Thesis, Université de Paris. 